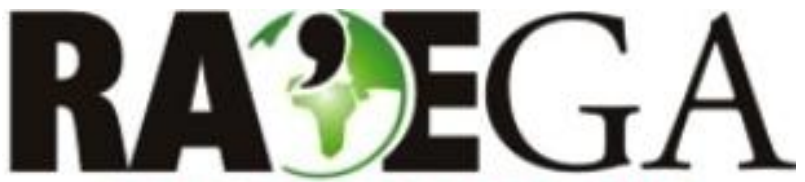

O ESPACYO GEOGRAFICO EM ANÁLISE

\title{
MAPEAMENTO DIGITAL DE SOLOS POR PEDOMETRIA COM BASE EM ATRIBUTOS TOPOGRÁFICOS DA BACIA HIDROGRÁFICA DO RIO PEQUENO-PARANÁ
}

\section{PRELIMINARY SOIL MAPPING BY PEDOMETRICS BASED ON TOPOGRAPHIC ATTRIBUTES OF PEQUENO BASIN}

\author{
Alexei Nowatzki \\ Colaborador do Laboratório de Biogeografia e Solos da Universidade Federal do Paraná (UFPR) \\ Departamento de Geografia \\ Curitiba, $P R$ \\ e-mail: nowatzki.a@gmail.com \\ Leonardo José Cordeiro Santos \\ Professor da Universidade Federal do Paraná (UFPR) \\ Departamento de Geografia \\ Curitiba, $P R$ \\ e-mail: santos.ufpr@gmail.com
}

Recebido em: 10/10/2013

Aceito em: 18/08/2014

\section{Resumo}

Os diferentes tipos de solos podem ser compartimentados de acordo com diversas características do relevo. A Pedometria pode se basear nas características dos atributos topográficos primários e secundários, que são gerados a partir de um Modelo Digital do Terreno (MDT) por técnicas de geoprocessamento. Esses atributos podem representar a distribuição de Unidades Geomórficas, que indicam a presença de determinados tipos de solos. Com o objetivo de realizar um mapeamento digital de solos, foram gerados quatro atributos para a bacia hidrográfica do rio Pequeno (Antonina/PR), sendo eles: Clinografia, Índice de Corrente de Máximo Fluxo, Índice Topográfico de Umidade e Índice de Capacidade de Transporte de Sedimentos. A partir das classes dos atributos, foram feitos cruzamentos das classes pelo método da Tabulação Cruzada que resultou na identificação de quatro Grupos: Grupo 1: Áreas planas e úmidas características de solos hidromórficos/flúvicos. Grupo 2: Terço médio de vertente com declives intermediários onde podem ocorrer os Cambissolos Háplicos. Grupo 3: Áreas de terço superior com fortes declives com associação de Cambissolos Háplicos com NeossolosLitólicos. Grupo 4: Áreas escarpadas de Serra com Neossolos Litólicose possibilidade de afloramentos rochosos. A partir destes grupos foi possível espacializar a distribuição dos potenciais solos da área de estudo. 
Palavras-chave: Modelo Digital do Terreno, Tabulação Cruzada, Cartografia Pedológica.

\section{Abstract}

The different types of soils can be compartmentalised according with various features of relief. The pedometricscan be based on the characteristics of primary and secondary topographic attributes, which are generated from a Digital Terrain Model (DTM) for geoprocessing techniques. These attributes may represent the distribution of Geomorphic Units, which indicate the presence of certain types of soils. In order to accomplish a digitalsoil mapping, four attributes were generated for the Pequenobasin (Antonina/PR), namely: Slope, Stream Power Index, Wetness Index and Sediment Transport Index. From the classes of attributes, crosses were made between classes by the Cross Tabulation method which resulted in the identification of four groups: Group 1: Flat areas of humid lowlands and fluvic features. Group 2: Middle slope with intermediate slopes where can occur Inceptisol. Group 3: Upper slope areas with steep slopes with Inceptisol associated with Leptosols. Group 4: Sierra escarped areas with Leptosols and possibility of rocky outcrops. From these groups, it was possible to spatialize the potential soil distribution of the study area

Keywords: Digital Terrain Model, Cross-Tabulation, Pedological Cartography.

\section{INTRODUÇÃO}

Estudos em pedologia e geomorfologia consideram que os solos estão contidos em praticamente todas as porções do relevo, pois ele tem sua história ligada à própria história do relevo. Este fator acaba remetendo ao princípio de que a distribuição dos solos na paisagem está bastante condicionada às formas do relevo terrestre.

Para Queiroz Neto (2011), os pedólogos buscam o entendimento da relação relevo/solo ou morfogênese/pedogênese, desde a conceituação inicial do russo V. V.Dokutchaev, que foi um dos primeiros estudiosos na ciência do solo. Ele priorizava o clima como um fator importante de formação dos solos, mas reconhecia também a importância do material de origem, da vegetação, da fauna e do relevo. Este autor ainda explica que existe uma forte influência da vertente (topografia) na distribuição dos solos, pois certas propriedades dos solos variariam ao longo das vertentes, como a granulometria, as bases trocáveis e outras características que são manifestadas no solo como resultado da circulação hídrica ao longo das vertentes.

Conforme destacam Ippolitiet al. (2005), as relações entre os solos e as formas da paisagem têm sido, por longo tempo, a base do mapeamento dos solos, 
pois os métodos que representam a superfície terrestre de acordo com um modelo morfológico mostraram potencial para melhorar a predição da ocorrência dos tipos de solos, visto que a posição na paisagem influencia os processos de formação e os atributos pedológicos.

As diferentes classes de solos em diferentes posições do relevo remontam à ideia de que os processos de sua formação também são diferentes para cada segmento de uma vertente. Frequentemente a porção superior de uma encosta se caracteriza pela erosão, a porção intermediária se caracteriza pelo transporte, e o sopé pela deposição dos sedimentos (COELHO, 2010).

Segundo este autor, as partes mais altas são mais drenadas, em relação as mais baixas, e esta diferença de drenagem é responsável pelas mudanças graduais nas características dos solos.

Valladares e Hott (2008) também destacam que as formas do relevo tem um grande impacto na distribuição dos solos por meio dos movimentos da água na vertente e por processos morfogenéticos atuantes. Vidal-Torrado et al. (2005), também elucidaram influência existente na distribuição dos solos pelo relevo e pela movimentação da água ao longo das vertentes.

Deste modo, estudos quantitativos têm sido desenvolvidos em uma área da ciência do solo denominada de pedometria, que se baseia no desenvolvimento de modelos numéricos ou estatísticos a partir de relações entre variáveis ambientais e o solo, os quais são aplicados a um banco de dados geográfico para criar um mapa preliminar, ou preditivo (MCBRATNEY et al., 2000 e TEN CATENet al., 2009).

Sirtoliet al.(2008a) e Silveira (2010) destacam que as técnicas de pedometria consistem, em mapear grupos de solos de acordo com as características morfológicas das vertentes, sendo possível inferir onde estarão, por exemplo, os solos com características hidromórficas, os mais desenvolvidos e os mais rasos.

A partir da inserção do geoprocessamento e do SIG (Sistema de Informações Geográficas) nos estudos ambientais, a pedologia pôde se beneficiar com a criação de um grande banco de dados digitais e ferramentas computacionais, como aqueles fornecidos pelo Modelo Digital do Terreno (MDT), que estão proporcionandouma evolução na pesquisa pedológica (McBRATNEYet al., 2003). 
Para Lagacherie (2008), um Mapeamento Digital (ou preditivo) de Solos (MDS) pode ser definido como "a criação e a população de sistemas de informação espacial do solo por modelos numéricos que inferem variações espaciais e temporais dos tipos e propriedades do solo a partir da observação e conhecimento do solo junto com variáveis relacionadas com o meio ambiente".

Segundo Coelho e Giasson (2010) um MDS se baseia na geração de sistemas de informações que permitem estabelecer relações matemáticas entre variáveis ambientais (atributos do terreno) e classes de solos e, assim, predizer a distribuição espacial dessas classes com significativa semelhança aos mapas gerados por meios convencionais. Utilizando a pedometria, é possível estabelecer diversas relações entre os atributos topográficos provenientes de um Modelo Digital do Terreno com os compartimentos pedológicos de forma a aplicá-las no mapeamento preliminar de solos.

As formas do relevo, possíveis de serem analisadas também pelo MDT, exercem um papel decisivo no tempo de exposição dos minerais do solo, na intensidade e direção do fluxo da água no perfil solo, influenciando, portanto, os processos pedogenéticos. $O$ estudo das diferentes formas do relevo torna-se portanto premissa básica para a execução de levantamentos de solo (CAMPOS et al., 2006).

Para Campos et al., (2006) a utilização de um Modelo Digital do Terreno (MDT) permite uma melhor visualização da inter-relação solo e paisagem através de associações da influência do relevo, do comportamento hídrico e da comunidade vegetal sobre os diferentes solos, permitindo estabelecer limites mais precisos e menos subjetivos entre os compartimentos pedológicos.

No entanto, Lagacherie (2008) adverte que um conjunto de dados cartográficos e topográficos de qualidade é fator chave para efetivar um MDS preciso e avaliar a qualidade dos seus resultados. $\mathrm{O}$ autor argumenta ainda que a disponibilidade destes dados tem sido um fator limitante e pode frear os avanços dos MDS, pois quanto menor a escala de detalhe dos mesmos, pior será a predição dos solos em um MDS.

Sirtoliet al.(2008a) destacam que o uso de MDT como técnica auxiliar em levantamentos de solos, constitui uma evolução no entendimento das relações solo- 
relevo e consequentemente, uma ferramenta importante para identificar e mapear áreas com solos de características similares.

O objetivo deste trabalho foi realizar um mapeamento digital de solos da bacia hidrográfica do Rio Pequeno pelo método da tabulação cruzada. Essa bacia foi escolhida em virtude dos tipos de solos encontrados nela, como os Cambissolos, Neossolos e Gleissolos, característicos dos compartimentos geomorfológicos Serra do Mar e Planície Litorânea do Estado do Paraná e pela disponibilidade de dados com escalas detalhadas da região.

A bacia hidrográfica do rio Pequeno (Figura 1) estálocalizada no município de Antonina, entre as coordenadas geográficas 2507'30"S e 2517'00"S; e entre 483' $30^{\prime \prime}$ e $48^{\circ} 44^{\prime} 00^{\prime} W$. A bacia faz limite com os municípios de Guaraqueçaba a leste e Campina Grande do Sul ao norte e está a aproximadamente 70 quilômetros de Curitiba no sentido SW-NE, com principal acesso feito pelas rodovias federais BR-116 ao norte e pela BR-277 ao sul. É interligada aos municípios costeiros do Paraná pelas rodovias estaduais PR-405 a leste e PR-340 ao sul.
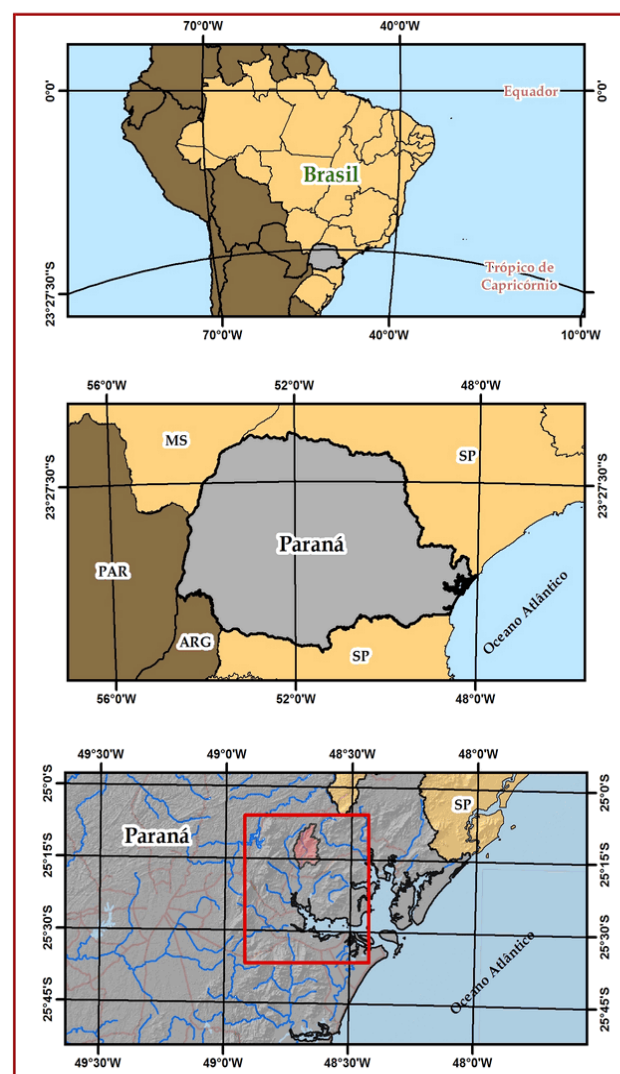

MAPA DE LOCALIZAÇÃO DA

BACIA HIDROGRÁFICA DO RIO PEQUENO
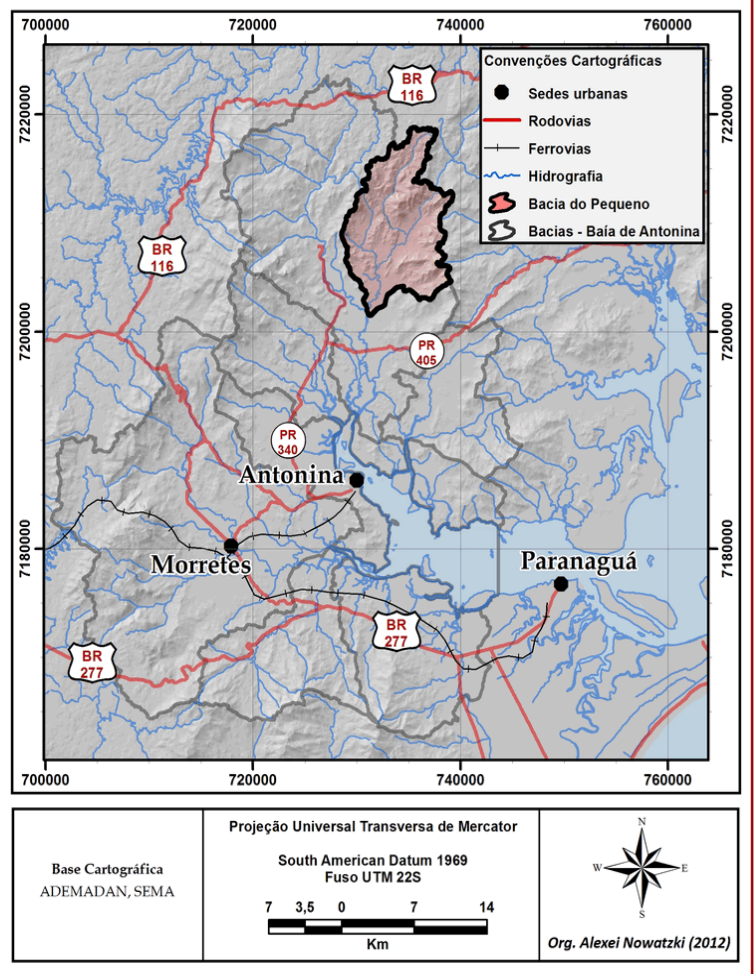

Figura 1: Localização da bacia hidrográfica do rio Pequeno. 
Essa bacia caracteriza-se hidrograficamente como de sexta ordem na hierarquização fluvial proposta por Strahler (1952). Ela possui $112,8 \mathrm{~km}^{2}$ de área e seu canal hídrico principal homônimo percorre aproximadamente 17 quilômetros. Seus principais afluentes são: rio da Sorte, rio do Quebra, Rio Pinheiro e Rio Gervásio. O comprimento total dos canais hídricos da bacia do Rio Pequeno é de $428,87 \mathrm{~km}$ e a densidade de drenagem situa-se em $3,9 \mathrm{~km} / \mathrm{km}^{2}$ (SILVA, 2010).

Em termos geológicos na bacia dorio Pequeno podem-se notar oscomplexos granítico-gnáissico, gnaissico-migmatítico, cachoeira e serra negra, além das unidades suíte álcali-granitos, intrusivasgranitóides e sedimentos recentes de planície litorânea (MINEROPAR, 2001).

Com relação aos aspectos geomorfológicos, a bacia é integrante da unidade fisiográfica Serra do Mar Paranaense em sua maior parte, limitada a noroeste com o Primeiro Planalto Paranaense ou Planalto de Curitiba. Na porção sul da bacia encontra-se a Planície Litorânea, conforme denominações de Maack (1981). A caracterização geomorfológica (Figura 2) inclui a descrição das Unidades Ambientais Naturais (UAN) apresentadas no Macrozoneamento do Litoral Paranaense (IPARDES, 1989). Nesta figura, pode-se ainda destacar que as porções de Serra ocupam a maior parte da bacia, bem como as Áreas Coluviais Montanhosas, ficando entre os compartimentos de Serra e de Planícies Aluviais.

A cobertura vegetacional se encontra em estágio de sucessão ecológica média e avançada de Floresta Ombrófila Densa dos tipos Altomontana, Montana, Submontana, de Terras Baixas e Aluvial (PARANÁ, 2002). Para elaborar esta caracterização na Figura 2, foram utilizados dados de Paula (2010).

Por fim, os aspectos pedológicos da Serra do Mar para Bigarella et. al. (1978) são resultantes da inter-relação existente entre os componentes do meio físico, como o relevo acidentado, o histórico de movimentos de massa, a alta pluviosidade e as diferentes texturas e estruturas das rochas matrizes. Existe a predominância de solos com horizontes pouco desenvolvidos nas encostas mais íngremes, como os Cambissolos e os Neossolos Litólicos (EMBRAPA, 2006). Estes autores ainda apontam que nas áreas de transição para a planície litorânea aparecem solos arenosos e hidromórficos nas áreas de deposição fluvial (Cambissolos Flúvicos, Neossolos Flúvicos e Gleissolos). 


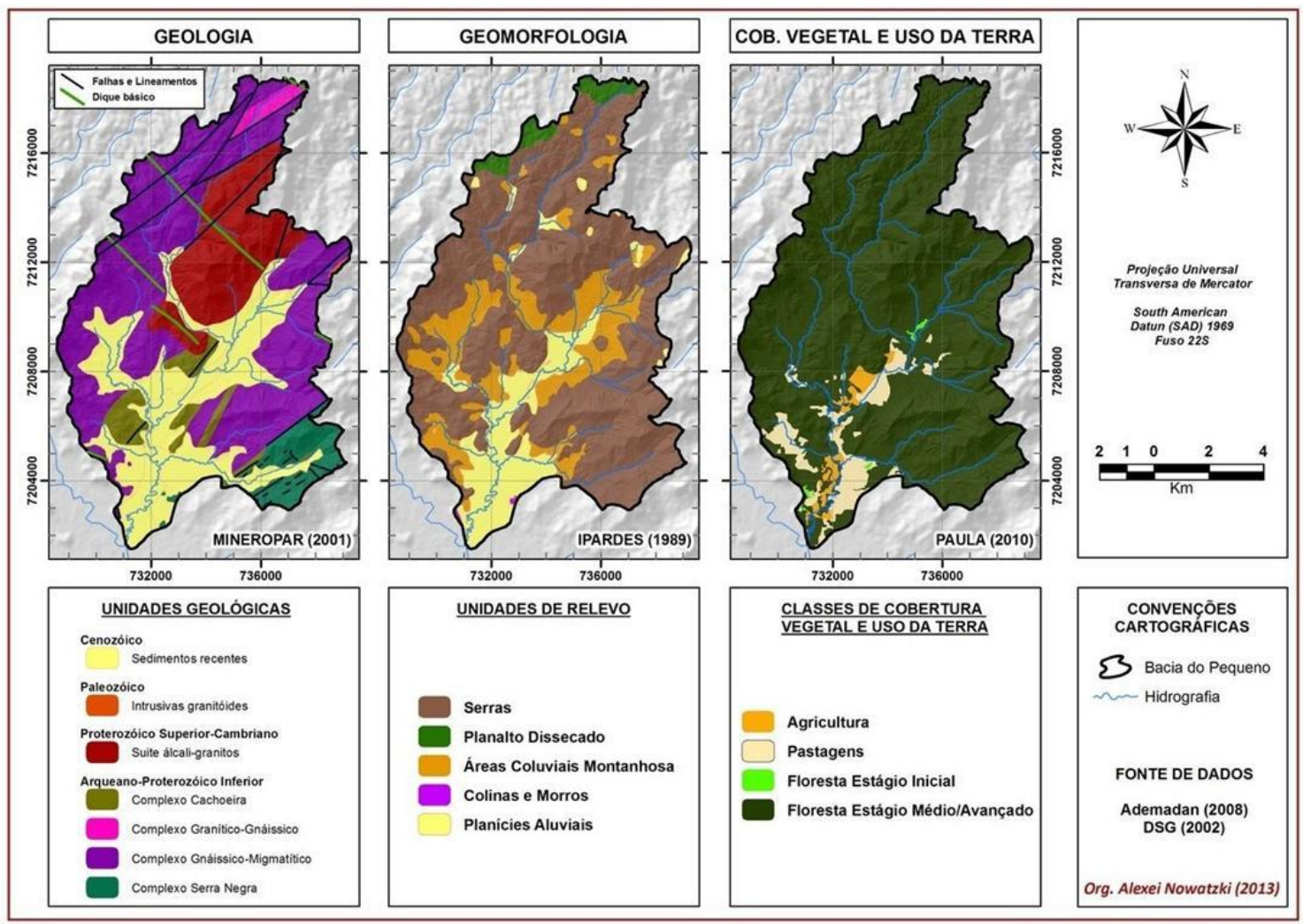

Figura 2: Mapa de caracterização Geológica, Geomorfológica e de Cobertura Vegetal e Uso da Terra da bacia hidrográfica do rio Pequeno.

\section{MATERIAL E MÉTODOS}

Os dados cartográficos utilizados neste trabalho foram elaborados a partir de cartas topográficas na escala 1:25.000 (curvas com equidistância de 10m), presentes em Paula (2010). Já a confecção do mapa preliminar de solos a partir da pedometria, foi feita a partir de variáveis geomorfométricas denominadas de atributos topográficos primários: Hipsometria $(Z)$, Declividade $(\alpha)$, Perfil $(\varphi)$ e Plano $(\psi)$ de Curvatura e atributos topográficos secundários: Índice de Corrente de Máximo Fluxo $(\Omega)$, Índice de Umidade (w) e Índice de Capacidade de Transporte de Sedimentos $(\tau)$ (MOORE et al., 1993, McBRATNEYet al., 2003 e SILVEIRA, 2010). Todos estes atributos são gerados a partir do MDT da bacia.

Conforme Moore et. al., (1993), as variáveis primárias seriam aquelas derivadas diretamente de um modelo do terreno; as secundárias são as variáveis que envolvem a combinação de variáveis primárias (geralmente índices geomorfométricos). 
Com as informações de curvas de nível e pontos cotados, foi possível elaborar o MDT da bacia. Estefoi gerado com o auxílio do software ArcGIS 9.3 (ESRI, 2009), em especial a ferramenta Topo toRaster. Esta ferramenta interpola uma superfície hidrologicamente correta a partir de polígonos, linhas e pontos, disponível no módulo Spacial Analyst, deste software. Os atributos topográficos primários foram gerados neste mesmo software e os secundários no SAGA 2.0.5. (SAGA, 1999).

As operações usadas na geração dosatributos topográficos foram executadas por meio de uma janela com nove nodos, (Figura 3). Esse método consiste em calcular os parâmetros de uma célula central e seus vizinhos em uma janela de oito células que se deslocam $3 \times 3$, cujo objetivo é obter o cálculo dos atributos topográficos (McBRATNEYet al., 2003 e SILVEIRA, 2010).

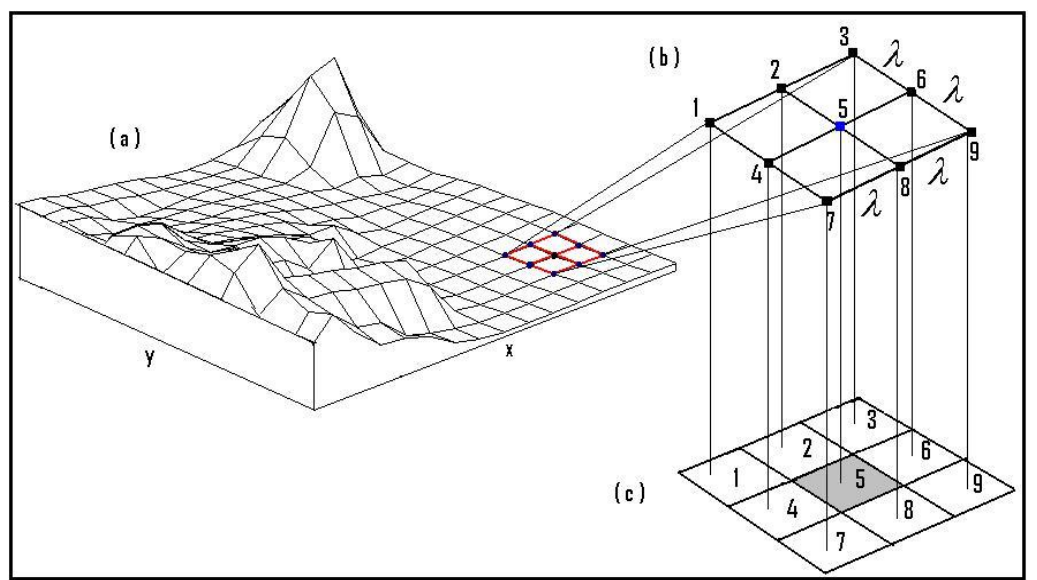

Figura 3: (a) Grade regular da superfície do solo; (b) Janela com nove nodos; (c) Janela com nove pixels.

Fonte: Silveira (2010)

Para tanto, é executada uma varredura com essa janela, sobre o conjunto total de dados (Figura 3-a) que representam a área estudada. Observa-se na Figura 3-b que a largura, ou espaçamento, da grade é de $\lambda$ metros. A Figura 3-c mostra a representação da grade na forma matricial. Isto é, cada ponto da grade é transformado em um pixel. Cada pixel possui um valor correspondente à elevação do ponto e uma largura de $\lambda$ metros (SILVEIRA, 2010). De posse dessa informação, os atributos topográficos primários e secundários puderam ser definidos usando um pixel de $10 \mathrm{~m}$, sendo que para este trabalho foram escolhidos os atributos Clinografia 
e os Índices: Corrente de Máximo Fluxo, Topográfico de Umidade e Capacidade de Transporte de Sedimentos, pois os mesmos proporcionaram uma melhor representação para os solos potenciais da região.

A clinografia (a), conforme Santos (2004) representa de forma contínua, a inclinação e as formas do relevo. Conforme o Sistema Brasileiro de Classificação de Solos (EMBRAPA, 2006), os tipos do relevo qualificam condições de declividade, comprimento de encostas e configuração superficial dos terrenos, que afetam as formas de modelado (formas topográficas) de áreas de ocorrência das unidades de solo (Quadro 1).

Quadro 1: Classes Clinográficas

\begin{tabular}{|c|c|}
\hline CLASSE CLINOGRÁFICA & TIPOS DO RELEVO \\
\hline 0 a $3 \%$ & Plano \\
\hline $3 a 8 \%$ & Suave Ondulado \\
\hline 8 a $20 \%$ & Ondulado \\
\hline 20 a $45 \%$ & Forte Ondulado \\
\hline $45 a$ a $75 \%$ & Montanhoso \\
\hline $75 \%<$ & Escarpado \\
\hline
\end{tabular}

Fonte: EMBRAPA (2006)

Os atributos secundários considerados no presente trabalho, baseados em Moore et al. (2003), são os parâmetros relacionados à processos de transportes de sedimentos e a movimentação da água superficial e subsuperficial no solo.

Segundo Silveira (2010) nos atributos topográficos secundários a discretização das classes é orientada pela morfologia do relevo da área e nas unidades de mapeamento de solos existentes. Os intervalos apresentam subjetividade na sua separação e os valores apresentados nos índices são adimensionais. Ou seja, é preciso ter um conhecimento prévio da área de estudo, mesmo que generalizado, pois só assim essa discretização poderá ser mais coerente com a real distribuição dos solos.

O Índice de Corrente de Máximo Fluxo $(\Omega)$ é a mensuração do poder erosivo da água corrente, com base no pressuposto de que a descarga é proporcional à acumulação de fluxo de montante. Prediz a erosão nas áreas de perfil convexo (aceleração do fluxo) e deposição em áreas de perfil côncavo (redução da velocidade de fluxo), (WILSON e GALLANT, 2000 apud SILVEIRA, 2010). 
O Índice Topográfico de Umidade (w), segundo Moore et al. (1993), Siefert e Santos (2012) e Silveira (2010) demonstra os efeitos do relevo na localização e extensão das áreas de acumulação de água pois é possível fazer uma separação dos solos com caráter hidromórfico, que ocorrem em relevo plano, de outras classes de solos que ocorrem em área planas e suave onduladas. Sirtoli (2008) ainda destaca que este índice é definido como uma função da declividade e da área de contribuição por unidade de largura ortogonal à direção do fluxo.

O Índice de Capacidade de Transporte de Sedimentos $(\tau)$, segundo Silveira (2010), mensura a capacidade de transporte de sedimentos, pois quanto maior a declividade do terreno e mais alto valor da área de contribuição, maior será a capacidade de transporte de sedimentos e consequentemente os solos formados nessa condição serão menos desenvolvidos.

A técnica da tabulação cruzada é empregada na integração das variáveis é por superposição de mapas ou álgebra de mapas (TOMLIN, 1983). Esta técnica indica o conjunto de procedimentos de análise espacial em geoprocessamento que produz novos dados a partir de funções de manipulação aplicadas a um ou mais mapas (SILVEIRA et al., 2012).

Conforme aponta Silveira (2010) esse método constitui na sobreposição das classes dos atributos topográficos na forma de matrizes, nas quais são executadas operações de cálculo dentro de um ambiente de SIG, considerando pesos atribuídos. Da mesma forma, Neto (2004) coloca que uma tabulação cruzada é entendida como uma tabela de informações de duas ou mais variáveis que são consideradas conjuntamente.

Massadet al. (2004) colocam que quando se deseja descrever uma relação entre duas variáveis qualitativas, os dados podem ser facilmente resumidos através de uma tabela cruzada ou de contingência. Eles destacam que este método se dá em uma tabela retangular, com linhas indicadoras para cada categoria da variável $X$, e colunas indicadoras para cada categoria da variável Y. Portanto, existe uma célula na tabela para qualquer combinação possível de valores de $\mathrm{X}$ e de $\mathrm{Y}$, sendo cada combinação representada por $(x, y)$.

$\mathrm{Na}$ bacia do Rio Pequeno, onde existam informações pedológicas preexistentes, as variáveis se mostram suficientes e adequadas na predição por 
tabulação cruzada porque nesse método, os atributos são discretizados e as classes são preliminarmente comparadas com mapas de solos preexistentes, fato que oferece informações prévias da relevância de cada atributo no processo de atribuição de pesos.

A integração de atributos topográficosfoi baseada nos critérios apontados por Silveira (2010) e Silveira et al. (2012), onde foram primeiramente atribuídos pesos às classes de cada um dos atributos utilizados, considerando o potencial de atuação da morfogênese. Este procedimento foi realizado no software ArcGis 9.3.1 com o módulo Spatial Analyst e os valores resultantes estão destacados noQuadro 2.

\begin{tabular}{|c|c|c|c|c|}
\hline PESOS / ATRIBUTOS & $w$ & $\Omega$ & $\alpha$ & $\tau$ \\
\hline $\mathbf{1}$ & $<7$ & $<30$ & $<3$ & $<0,004$ \\
\hline $\mathbf{2}$ & $7 \mathrm{a} 8$ & $30 \mathrm{a} 60$ & $3 \mathrm{a} 8$ & 0,004 a 0,02 \\
\hline $\mathbf{3}$ & $8 \mathrm{a} 9$ & $60 \mathrm{a} 300$ & 8 a 20 & 0,02 a 0,05 \\
\hline $\mathbf{4}$ & $9 \mathrm{a} 10$ & $300<$ & 20 a 45 & 0,05 a 0,08 \\
\hline $\mathbf{5}$ & $10 \mathrm{a} 11$ & ------ & 45 a 75 & $0,08<$ \\
\hline $\mathbf{6}$ & $11<$ & ------- & $75<$ & ------- \\
\hline
\end{tabular}

Quadro 2: Síntese da divisão dos pesos das classes dos atributos topográficos

Para cada atributo foram feitos testes com número de intervalos variáveis, analisando-se sempre os histogramas de acordo com as distribuições dos pixels, bem como foi observado às respostas das divisões das classes em relação às curvas de nível e também os mapeamentos preexistentes presentes na área.

De acordo com os estudos de Silveira (2010), a partir da integração dos valores dos atributos topográficos, chega-se às Unidades Geomórficas (IRVIN et al., 1997), ou Superfícies Geomórficas (VIDAL-TORRADO et al,. 2005), queexpressam a dinâmica da paisagem em função da morfologia do relevo. Por meio da identificação de características resultantes do cruzamento entre atributos do relevo, os solos podem ser agrupados em unidades preliminares de mapeamento, nos quais podem ser encontrados solos com propriedades homogêneas (HUDSON, 1992).

A matriz representada no Quadro 3, se refere aos valores dos índices Topográfico de Umidade e Corrente de Máximo Fluxo. Para o primeiro, foram considerados seis intervalos, sendo que os maiores pesos representam áreas com maior acúmulo de umidade e, os menores valores as áreas melhor drenadas. Já 
para o segundo índice, os pesos são crescentes em função do aumento na corrente de fluxoe para esta bacia foram determinados quatro intervalos.

\begin{tabular}{|c|c|c|c|c|c|c|c|}
\hline \multirow{2}{*}{\multicolumn{2}{|c|}{ CLASSES }} & \multicolumn{6}{|c|}{ TOPOGRÁFICO DE UMIDADE } \\
\hline & & $w 6$ & w5 & w4 & $w 3$ & $w 2$ & $w 1$ \\
\hline \multirow{4}{*}{ 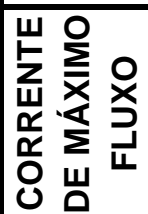 } & $\Omega 1$ & 16 & $\overline{15}$ & $\overline{14}$ & 13 & 12 & 11 \\
\hline & $\Omega 2$ & 26 & 25 & 24 & 23 & 22 & 21 \\
\hline & $\Omega 3$ & 36 & 35 & 34 & 33 & 32 & 31 \\
\hline & $\Omega 4$ & 46 & 45 & 44 & 43 & 42 & 41 \\
\hline
\end{tabular}

Quadro 3: Matriz de tabulação do atributo Topográfico de Umidade com Corrente de Máximo Fluxo

Esta matriz de tabulação possui 24 combinações, sendo que todas aparecem na bacia do rio Pequeno. As combinações resultantes foram incorporadas em quatro agrupamentos, de acordo com características Geomorfológicas e Hidrológicas, conforme o Quadro 4.

\begin{tabular}{|c|c|c|c|}
\hline AGRUPAMENTO & COMBINAÇÕES & $\begin{array}{c}\text { CARACTERÍSTICAS DE } \\
\text { VERTENTE }\end{array}$ & $\begin{array}{c}\text { SATURAÇÃO E } \\
\text { ESTAGNAÇÃO } \\
\text { HíDRICA }\end{array}$ \\
\hline 1 & $\begin{array}{c}14,15,16,25,26,36 \text { e } \\
46\end{array}$ & $\begin{array}{c}\text { Áreas aplainadas e mal } \\
\text { drenadas em terço inferior }\end{array}$ & Alta \\
\hline 2 & $\begin{array}{c}11,12,13,21,22,23, \\
24,33,34 \text { e } 35\end{array}$ & Áreas de terço médio & Média \\
\hline 3 & $31,32,44$ e 45 & Áreas de terço superior & Baixa \\
\hline 4 & 41,42 e 43 & $\begin{array}{c}\text { Áreas escarpadas de terço } \\
\text { superior }\end{array}$ & Muito baixa \\
\hline
\end{tabular}

Quadro 4: Síntese das características resultantes da matriz de tabulação do atributo Topográfico de Umidade com Corrente de Máximo Fluxo

O agrupamento 1, se refere as porções da paisagem que possuem alta saturação e estagnação hídrica. São coincidentes com as planícies aluviais (Figura 2) e podem indicar a presença de solos hidromórficos. O agrupamento de número 2 se refere às porções onde existe saturação e estagnação hídrica menor que a do agrupamento 1, não sendo possível encontrar condições ideais para formação de solos hidromórficos. São encontrados ainda em porções coluvionares e em áreas serranas de diversas litologias. O terceiro agrupamento possui uma baixa saturação e estagnação hídrica sendo encontrado em áreas serranas. Por fim, o agrupamento 4 se refere às áreas com valores de saturação e estagnação hídrica quase nula. 
Ocorrem em porções escarpadas da Serra do Mar, sendo encontradas majoritariamente no Complexo Gnáissico-Migmatitico.

A segunda matriz de tabulação, representada no Quadro 5, apresenta as classes dos pesos dos atributos Capacidade de Transporte de Sedimentos e de Clinografia. O primeiro foi dividido em cinco intervalos, sendo que os maiores pesos representam áreas com potencial erosivo grande e os valores menores para áreas de deposição. Já os pesos das classes de Clinografia são crescentes em função do aumento do seu valor em \%.

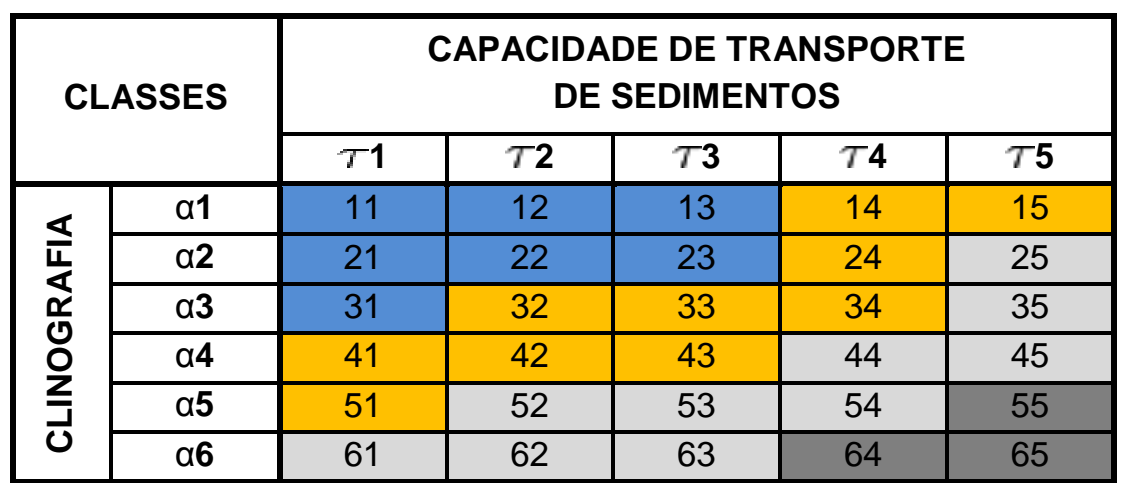

Quadro 5: Matriz de tabulação do atributo Capacidade de Transporte de Sedimentos com Clinografia

Esta matriz de tabulação possui 30 combinações e as mesmas foram agrupadas de acordo com critérios Geomorfológicos (relação pedogênese e morfogênese), ou seja, áreas onde ocorrem processos deposicionais e asonde predominam os processos erosivos, pois esses dois atributos podem indicar ambos os processos (SIRTOLI, 2008 e SILVEIRA, 2010), (Quadro 6).

\begin{tabular}{|c|c|c|c|}
\hline AGRUPAMENTO & COMBINAÇÕES & $\begin{array}{c}\text { CARACTERÍSTICAS DE } \\
\text { VERTENTE }\end{array}$ & $\begin{array}{c}\text { RELAÇÃO PEDOGÊNESE } \\
\text { E MORFOGÊNESE }\end{array}$ \\
\hline 1 & $\begin{array}{c}11,12,13,21 \\
22,23 \text { e } 31\end{array}$ & Áreas planas (planícies) & $\begin{array}{l}\text { Somente processos } \\
\text { deposicionais }\end{array}$ \\
\hline 2 & $\begin{array}{c}14,15,24,32 \\
33,34,41,42,43 \\
\text { e } 51\end{array}$ & $\begin{array}{c}\text { Áreas de terço médio } \\
\text { com declives } \\
\text { intermediários }\end{array}$ & $\begin{array}{l}\text { Processos erosivos } \\
\text { atuantes em áreas de } \\
\text { colúvio } \\
\end{array}$ \\
\hline 3 & $\begin{array}{c}25,35,44,45 \\
52,53,54,61,62 \\
\text { e } 63 \\
\end{array}$ & $\begin{array}{l}\text { Áreas de terço superior } \\
\text { com fortes declives }\end{array}$ & $\begin{array}{l}\text { Predominância de } \\
\text { processos erosivos }\end{array}$ \\
\hline 4 & 55,64 e 65 & $\begin{array}{l}\text { Áreas escarpadas de } \\
\text { Serra }\end{array}$ & $\begin{array}{c}\text { Somente processos } \\
\text { erosivos }\end{array}$ \\
\hline
\end{tabular}

Quadro 6: Síntese das características resultantes da matriz de tabulação do atributoCapacidade de Transporte de Sedimentos e de Clinografia 
Esta matriz de tabulação resultou em quatro agrupamentos, da mesma forma que a primeira (Quadro 3). O primeiro agrupamento foi definido a partir das áreas mais planas da bacia, coincidindo com as planícies aluviais e sedimentos cenozoicos (Figura 2). São áreas onde os processos deposicionais predominam em função dos processos erosivos. O agrupamento 2 indica áreas onde existem processos erosivos de intensidade variando de baixa a intermediária em áreas coluviais. O terceiro agrupamento se refere às áreas onde existe uma predominância de processos erosivos em função dos deposicionais. E por ultimo, o agrupamento 4 foi escolhido para áreas onde apenas ocorrem processos erosivos.

A partir das informações presentes no Quadro 3 e 5, foi construída a matriz de tabulação final. Existem no total 16 combinações, contudo, para a bacia em questão foram encontrados 15, conforme o Quadro 7.

\begin{tabular}{|c|c|c|c|c|c|}
\hline \multicolumn{2}{|c|}{ CLASSES } & \multicolumn{4}{|c|}{$\alpha \mathrm{e} \tau$} \\
\cline { 2 - 6 } & $\mathbf{1}$ & $\mathbf{2}$ & $\mathbf{3}$ & $\mathbf{4}$ \\
\hline \multirow{3}{*}{3} & $\mathbf{1}$ & 11 & 12 & 13 & 14 \\
\cline { 2 - 6 } & $\mathbf{2}$ & 21 & 22 & 23 & 24 \\
\cline { 2 - 6 } $\mathrm{a}$ & $\mathbf{3}$ & 31 & 32 & 33 & 34 \\
\cline { 2 - 6 } & $\mathbf{4}$ & 41 & 42 & 43 & 44 \\
\hline
\end{tabular}

Quadro 7: Matriz de tabulação para obtenção das Unidades Geomórficas

Cabe destacar que a combinação 21 não se enquadrou no Grupo 1, pois mesmo que algumas áreas desta combinação estejam na planície, outras áreas estão distribuídas em porções da vertente, bem como em alguns topos aplainados. Já a combinação 31 foi enquadrada no Grupo 1 por se localizar majoritariamente em áreas de planície da bacia. O Quadro 8 sintetiza as informações desta ultima tabulação.

\begin{tabular}{|c|c|c|}
\hline AGRUPAMENTO & COMBINAÇÕES & CARACTERÍSTICAS PRINCIPAIS \\
\hline 1 & 11,12 e 31 & Áreas planas e úmidas \\
\hline 2 & $13,21,22,23,32,41$ e 42 & $\begin{array}{c}\text { Áreas de terço médio de vertente com } \\
\text { declives intermediários }\end{array}$ \\
\hline 3 & 14,33 e 43 & $\begin{array}{c}\text { Areas de terço superior com fortes } \\
\text { declives }\end{array}$ \\
\hline 4 & 34 e 44 & Áreas escarpadas de Serra \\
\hline
\end{tabular}

Quadro 8: Síntese das características das Unidades Geomórficas 
Todas as escolhas dos agrupamentos dos valores resultantes das tabulações cruzadas foram feitas a partir de análises de características pedológicas das classes de solos encontradas nas verificações de campo.

\section{RESULTADOS E DISCUSSÕES}

Os atributos topográficos Clinografia e os Índices Corrente de Máximo Fluxo, Topográfico de Umidade e Capacidade de Transporte de Sedimentos, foram mapeados conforme ilustram a Figura 4, Figura 5,Figura 6 eFigura 7. 

HIDROGRÁFICA DO RIO PEQUENO-PARANÁ

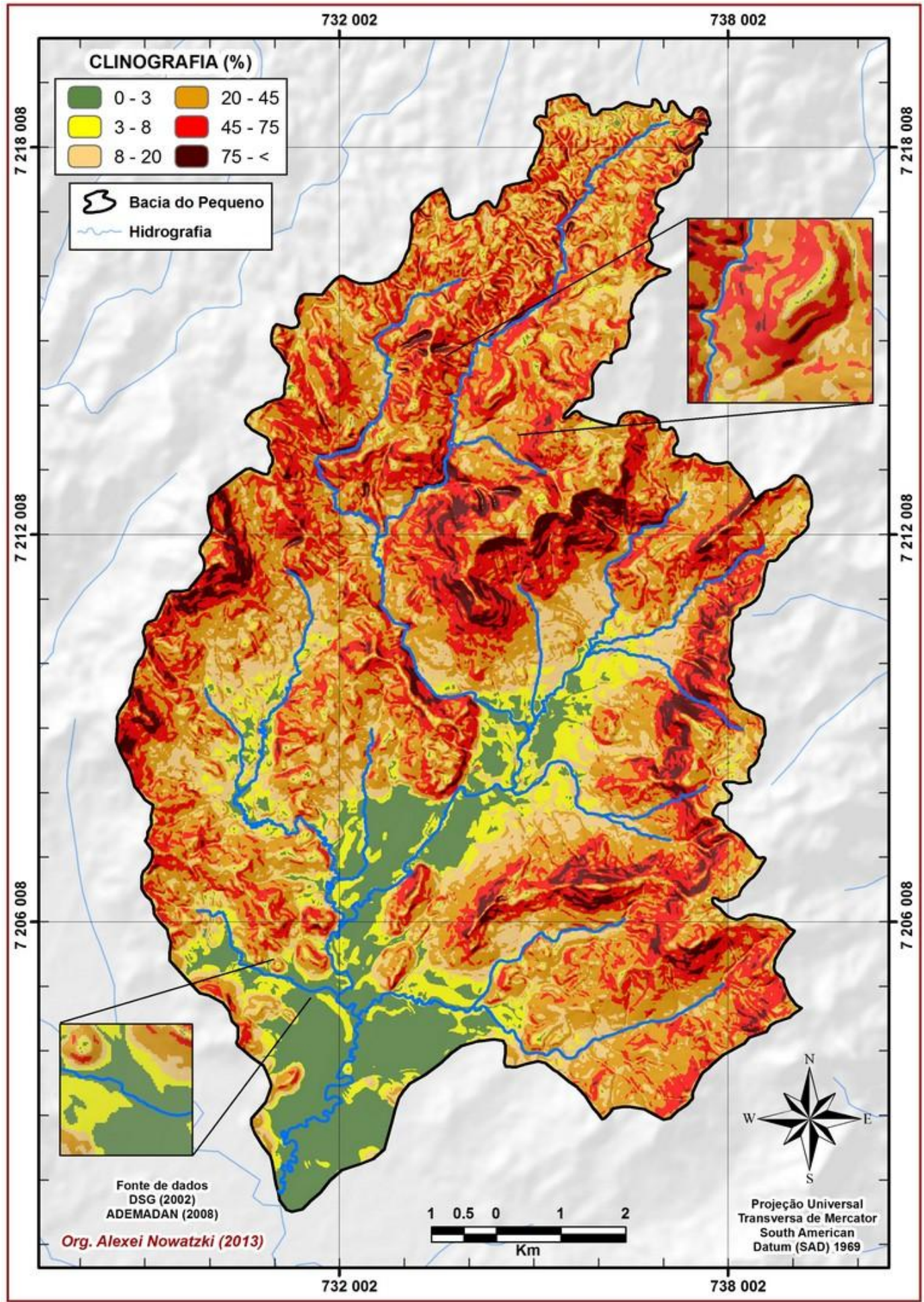

Figura 4: Mapa de classes Clinográficas 


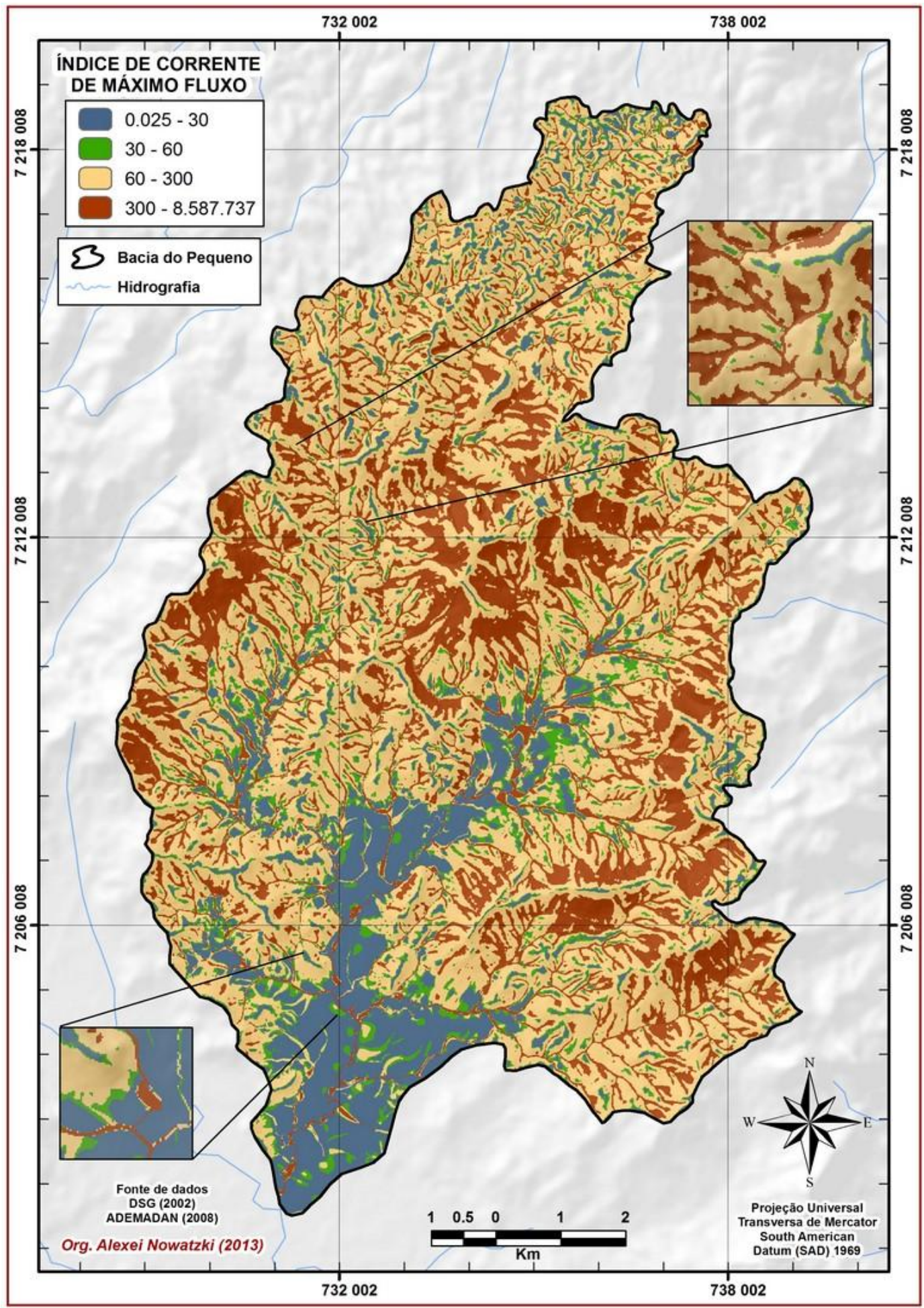

Figura 5: Mapa do Índice de Corrente de Máximo Fluxo 


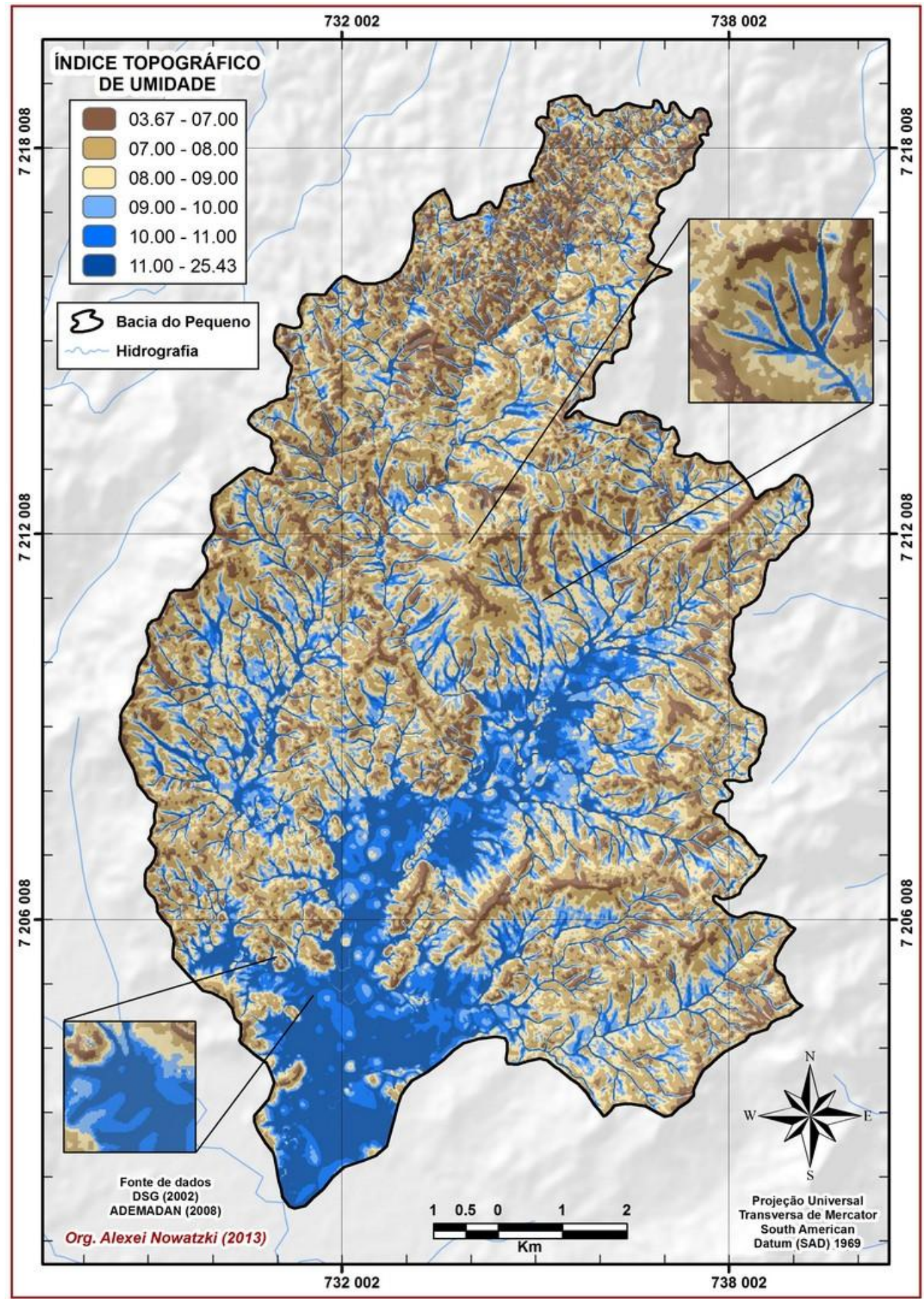

Figura 6: Mapa do Índice Topográfico de Umidade 


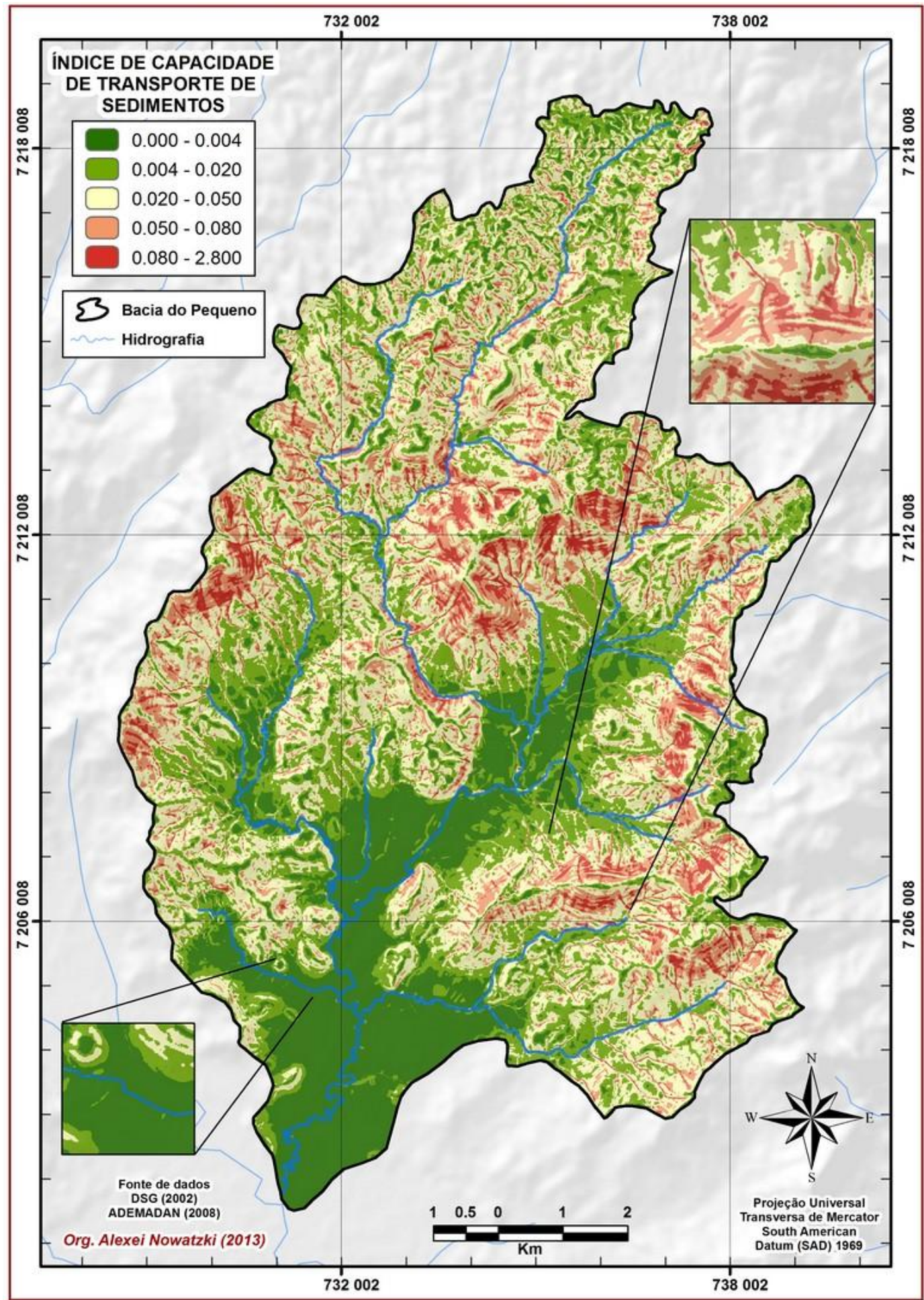

Figura 7: Mapa do Índice de Capacidade de Transporte de Sedimentos

A partir destes atributos topográficos e dos cruzamentos por tabulação cruzada dos índices (Topográfico de Umidade com Corrente de Máximo Fluxo e Clinografia com Capacidade de Transporte de Sedimentos) chegou-se na 
distribuição espacial das Unidades Geomórficas resultantes destes cruzamentos conforme ilustra a Figura 8.

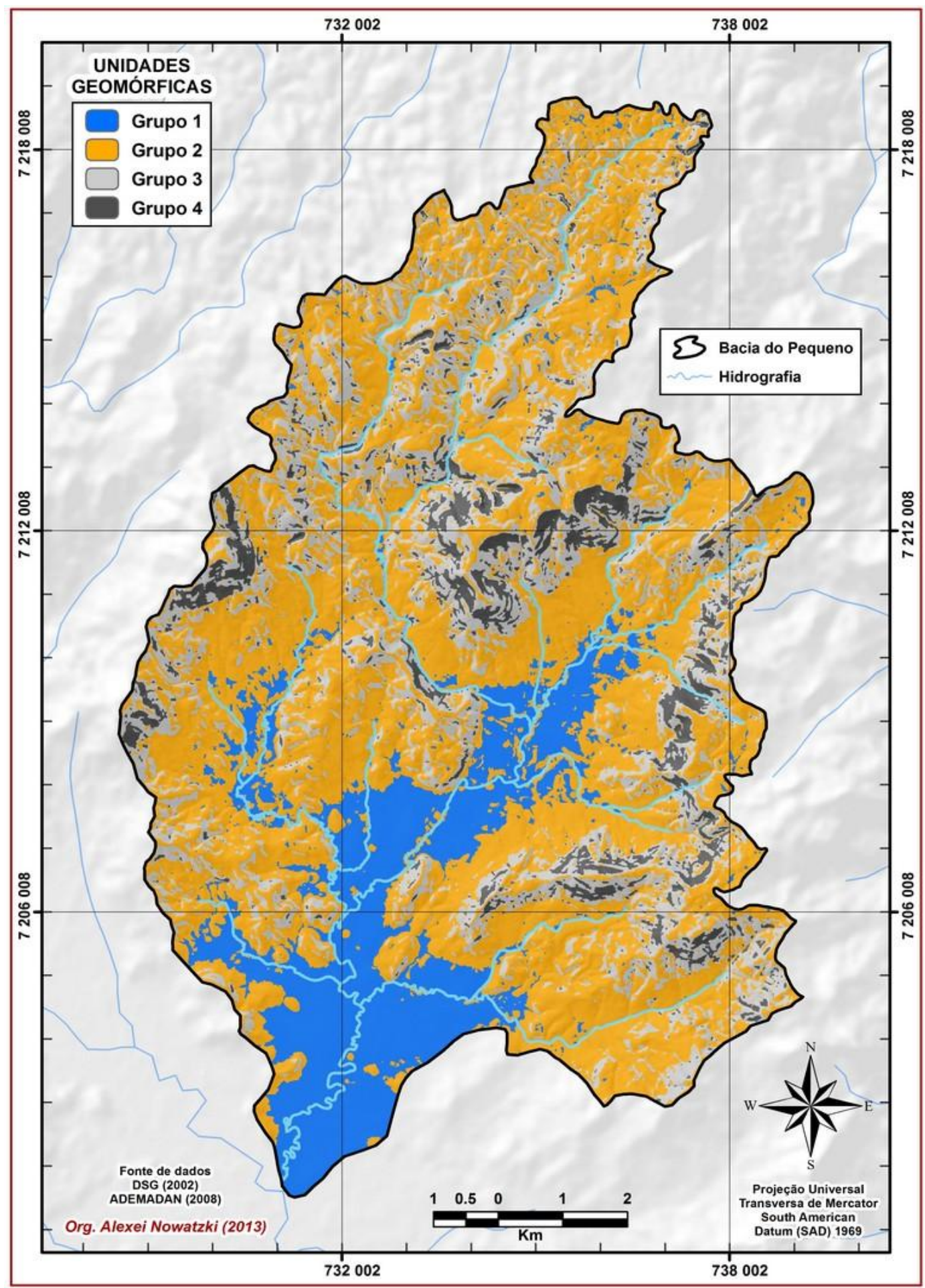

Figura 8: Grupos de unidades geomórficasgeradas por tabulação cruzada 
A Tabela 1 demonstra a proporção de área ocupada pelosgrupos de unidades geomórficas mapeados.

Tabela 1: Cálculo das áreas dos grupos referentes às Unidades Geomórficas

\begin{tabular}{|c|c|c|c|}
\hline GRUPO & TIPOS DE SOLOS & ÁREA (KM²) & ÁREA (\%) \\
\hline 1 & Hidromórficos e Flúvicos & 18,1 & 16,0 \\
\hline 2 & Cambissolos & 60,8 & 53,9 \\
\hline 3 & Cambissolos + Neossolos Litólicos & 27,2 & 24,2 \\
\hline 4 & Neossolos Litólicos & 6,7 & 5,9 \\
\hline & TOTAL & 112,8 & 100,0 \\
\hline
\end{tabular}

Para o Grupo 1, o Índice Topográfico de Umidade apontou áreas com valores elevados, característico de áreas úmidas. Pelo Índice de Corrente de Máximo Fluxo as áreas de planície aluvial provenientes de Sedimentos Cenozóicos, são áreas onde existe uma acumulação hídrica e os valores deste índice são extremamente baixos.

Pela Clinografia também é possível perceber uma grande coincidência entre as áreas com vertentes abaixo de $8 \%$. Os valores do Índice de Capacidade de Transporte de Sedimentos são baixos, pois estas áreas representam porções do relevo, onde os processos deposicionais e pedogenéticos predominam sobre os processos erosivos e morfogenéticos. A partir destas características, sugere-se que este grupo seja enquadrado como solos de provável caráter hidromórfico e flúvico.

Os solos do Grupo 2 aparecem no terço inferior da vertente na sequencia dos solos com caráter hidromórfico. Na área de estudo estão presentes a partir do contato da planície aluvial com as áreas coluviais montanhosas e em alguns casos de áreas serranas. Estes solos se diferem dos hidromórficos/flúvicos por apresentarem tonalidades mais amareladas com matiz 5YR. Com relação à Clinografia, os valores estão entre 8 e 45\%, sendo que, nas amostras coletadas em campo, nos declives menores, os solos possuíam maior profundidade no horizonte B.

Contudo, percebeu-se uma grande quantidade de minerais primários (alteráveis), fato que não permite enquadrar como Latossolos. Para Índice de Capacidade de Transporte de Sedimentos, estes solos aparecem em valores intermediários e em alguns casos valores baixos, por estarem situados em porções coluvionares, onde existe certo equilíbrio no balanço pedogênese/morfogênese. 
Para o Índice Topográfico de Umidade, os Cambissolos são percebidos apenas em valores intermediários da mesma forma que o Índice de Corrente de Máximo Fluxo. Para este grupo, é sugerido o enquadramento em Cambissolos em concordânciacom os mapeamentos pedológicos preexistentes na região onde estão mapeados Cambissolos Háplicos.

O Grupo 3possui solos de transição entre o Grupo 2 com o Grupo 4, com profundidades menores que do Grupo 2, visto que são encontrados em terços superiores das vertentes. Estão localizados em porções mais montanhosas da bacia com valores clinográficos altos (de 45 a 75\%). O Índice de Capacidade de Transporte de Sedimentos nestas porções possui valores de intermediários a altos, pois este grupo fica caracterizado por porções onde existe uma predominância de processos erosivos.

Já para os Índices Topográfico de Umidade e de Corrente de Máximo Fluxo, os valores resultaram de intermediários a baixos, pois como são áreas de alta clinografia e por se localizarem em porções de terço superior de vertente, existe poucoacumulo de água no solo. A partir destas informações, é possível inferir que ocorra nestas áreas uma associação de Neossolos Litólicos com Cambissolos.

O ultimo grupo (4) pertence aos solos mais rasos da bacia e os menos desenvolvidos, sendo que em alguns casos pode existir afloramento rochoso, conforme foi observado em campo e corroborado pelos valores dos atributos topográficos.

Os solos rasos se encontram em porções escarpadas com clinografia acima de $75 \%$, o que remete a ideia de que existem praticamente apenas processos erosivos atuantes. Desta forma, acredita-se que exista apenas horizonte $A$, extremamente raso sobre uma rocha subjacente. O Índice de Capacidade de Transporte de Sedimentos possui valores extremamente altos (morfogênese atuante) da mesma forma que para os Índices restantes. A partir destas características, sugere-se que este grupo represente os Neossolos Litólicos.

\section{CONSIDERAÇÕES FINAIS}

O estudo dos atributos topográficos bem como a sua discretização em classes, foi essencial no entendimento das relações do relevo com a distribuição dos 
solos na paisagem da bacia do rio Pequeno. O cruzamento por tabulação cruzada desses atributos possibilitou realizar agrupamentos que resultaram em grupos de Unidades Geomórficas, sendo possível realizar o objetivo de produzir um MDS da bacia do Rio Pequeno. Através dos resultados atingidos, conclui-se que as características do relevo local (Planícies e Serras), condicionam a espacialidade dos solos, expressando a relação existente entre essas duas variáveis.

Os atributos Topográfico de Umidade, Corrente de Máximo Fluxo, Capacidade de Transporte de Sedimentos e Clinografia apresentaram uma melhor relação com os tipos de solos encontrados em regiões de planícies aluviais, como os solos hidromórficos e os ocorrentes na Serra do Mar, como Cambissolos e Neossolos Litólicos, que são menos desenvolvidos e rasos.

A qualidade do MDT da bacia do rio Pequeno foi fundamental para o êxito do trabalho, pois as curvas de nível utilizadas no trabalho possuíam equidistância de $10 \mathrm{~m}$.

O método da tabulação cruzada se mostrou eficiente na espacialização das Unidades Geomórficas, pois com a álgebra de mapas foi possível predizer ambientes em que pudessem ocorrer diferentes tipos de solos e contribuir para uma melhor espacialização dos mesmos.

Para melhor validação dos grupos mapeados para o rio Pequeno, serão utilizados futuramente métodos comparativos com mapeamentos pedológicos preexistentes da região, para que se possa averiguar o grau de assertividadeentre 0 mapeamento tradicional e digital.

\section{REFERÊNCIAS BIBLIOGRÁFICAS}

BIGARELLA, J.J.; BECKER, R.D.; MATOS, D.J.; WERNER, A. A Serra do Mar e a Porção Oriental do Estado do Paraná. Curitiba: ADEA/Sec. Est. Planejamento/PR, 1978.

CAMPOS, M.C.C.; CARDOZO, N.P.; MARQUES JÚNIOR, J. Modelos de paisagem e sua utilização em levantamentos de pedológicos. Revista de Biologia e Ciências da Terra, v. 6, n. 1, 2006.

COELHO, F.F. Comparação de métodos de mapeamento digital de solos através de variáveis geomorfométricas e sistemas de informações geográficas. 
Porto Alegre, 80 f. Dissertação (Mestrado em Sensoriamento Remoto). Programa de pós-graduação em Sensoriamento Remoto. Centro estadual de pesquisas em Sensoriamento Remoto e Meteorologia. Universidade Federal do Rio Grande do Sul. 2010.

COELHO, F.F.; GIASSON, E. Métodos para mapeamento digital de solos com utilização de sistema de informação geográfica. Revista Ciência Rural, Santa Maria, v.40, n.10. Outubro, 2010.

EMBRAPA (Empresa Brasileira de Pesquisa Agropecuária). Sistema Brasileiro de Classificação de Solos. Centro Nacional de Pesquisa de Solos. 2. Ed. Rio de Janeiro: Embrapa Solos, 2006.

ESRI. ArcGis 9.3.1., Spatial Analyst, 3D Analyst. Environmental Systems Research Institute, 2009.

HUDSON, B.D. The soil survey as a paradigm-based science.Journal Soil Science Society of America, v.56, p.836-841, 1992.

IPARDES (Instituto Paranaense de Desenvolvimento Econômico e Social) / Fundação Édison Vieira. Zoneamento do Litoral Paranaense. Curitiba, Convênio SEPL (Secretaria de Estado do Planejamento e Coordenação Geral) /IPARDES. 175p. 1989.

IPPOLITI, G.A.; Costa, L.M.; SCHAEFER, C.E.G.R.; FILHO, E.I.F.; GAGGERO, M.R. Análise digital do terreno: ferramenta na identificação de pedoformas em microbacia na região de "Mar de Morros" (MG). Rev. Bras. Ciênc. Solo, Viçosa , v. 29, n. 2, Apr. 2005.2 Disponível em: http://www.scielo.br/scielo.php?script=sci_arttext\&pid=S0100$06832005000200012 \&$ Ing=en\&nrm=iso. Acesso em: 01 fev. 2013.

IRVIN, B.J.; VENTURA, S.J.; SLATER, B.K. Fuzzy and Isodata classification of landform elements from digital terrain data in Pleasant alley. Geoderma, v.77, p. 137-154, 1997.

LAGACHERIE P. Digital Soil Mapping: A State of the Art. In: Digital Soil Mapping with Limited Data, A.E. Hartemink et al. (eds.). Springer Science+Business Media B.V. 2008.

MAACK, R.R. Geografia Física do Estado do Paraná. 2. ed. Curitiba: Ed. Olympio, 1981. 
MASSAD, E.; MENEZES, R.X.; SILVEIRA, P.S.P.; ORTEGA, N.R.S. Métodos quantitativos em Medicina. Ed. Manole. Barueri, São Paulo, 2004.

McBRATNEY, A.B.; ODEH, I.O.A.; BISHOP, T.F.A.; DUNBAR, M.S.; SHATAR, T.M. An overview of pedometric techniques for use in soil survey.Geoderma, v. 97, n. 3-4, p.293-327, 2000.

McBRATNEY, A.B.; MENDONÇA-SANTOS, M.L.; MINASNY, B. On digital soil mapping.Geoderma, v. 117, p. 3-52, 2003.

MINEROPAR (MINERAIS DO PARANÁ S/A). Atlas geológico do Estado do Paraná. 2001.

MOORE, I.D.; GESSLER, P.E.; NIELSEN, G.A.; PETERSON, G.A. Soil attribute prediction using terrain analysis. Soil Science Society American Journal. v. 57, p. 443-452, 1993.

NETO, P.V. Estatística descritiva: Conceitos básicos. São Paulo. 2004.

PAULA, E.V. Análise da Produção de Sedimentos na Área de Drenagem da Baía de Antonina/PR uma abordagem geopedológica. Curitiba, $158 \mathrm{f}$. Tese (Doutorado em Geografia). Departamento de Geografia, Setor de Ciências da Terra, Universidade Federal do Paraná. 2010.

PARANÁ. Secretaria de Estado do Meio Ambiente e Recursos Hídricos. Programa Floresta Atlântica. Mapeamento da Floresta Atlântica do Estado do Paraná. Relatório final.Curitiba, 2002.

QUEIROZ NETO, J.P. Geomorfologia e Pedologia. Revista Brasileira de Geomorfologia. Vol. 1 p.59-67. São Paulo, 2000.

QUEIROZ NETO, J.P. Relações entre as vertentes e os solos: revisão de conceitos. Revista Brasileira de Geomorfologia - v. 12, no 3, 2011.

ROCHA, C.H.B. Geoprocessamento Tecnologia Transdiciplinar. Cap. 9 - Modelo Digital do Terreno. Minas Gerais: Ed. Do Autor, 2000.

ROSSITER, D.G. Digital Soil Mapping as a Component of Data Renewal for Areas with Sparse Soil Data Infrastructures In: Digital Soil Mapping with Limited Data, A.E. Hartemink et al. (eds.). Springer Science+Business Media B.V. 2008 
SAGA, System for Automated Geoscientific Analyses. SAGA Graphical User Interface Version: 2.0.5. SAGA Application Programming Interface - Version: 2.0.5, 1999.

SANTOS, R.F. Planejamento ambiental: teoria eprática. São Paulo: Oficina de Textos, 2004.

SIEFERT, C.; SANTOS, I. Mecanismos de geração de escoamento e áreas hidrologicamente sensíveis: Uma abordagem hidrogeomorfológica para delimitação de Áreas de Preservação Permanente. Ra'e Ga - 0 Espaço Geográfico em Análise, 24, mar. 2012. Disponível em: http://ojs.c3sl.ufpr.br/ojs2/index.php/raega/article/view/26216. Acesso em: 04 Ago. 2013.

SILVA, J.M.F. Caracterização e mapeamento das unidades geomorfológicas da Bacia do Rio Pequeno, Antonina - PR. Curitiba, 95 f. Dissertação (Mestrado em Geografia). Departamento de Geografia, Setor de Ciências da Terra, Universidade Federal do Paraná. 2010.

SILVEIRA, C.T. Análise digital do relevo na predição de unidades preliminares de mapeamento de solos: Integração de atributos topográficos em Sistemas de Informações Geográficas e redes neurais artificiais. Curitiba, 153 f. Tese (Doutorado em Geografia). Departamento de Geografia, Setor de Ciências da Terra, Universidade Federal do Paraná. 2010.

SILVEIRA, C.T.; OKA-FIORI, C.; SANTOS, L.J.C.; SIRTOLI, A.V.; SILVA, C.R. Pedometria apoiada em atributos topográficos comoperações de tabulação cruzada por álgebra de mapas. Revista Brasileira de Geomorfologia. Vol. 13, n 2. 2012.

SIRTOLI, A.V. Mapeamento de Solos Com Auxílio da Geologia, Atributos do Terreno e Índices Espectrais Integrados Por Redes Neurais Artificiais. Universidade Federal do Paraná. Curitiba, 114f. Tese (Doutorado em Geologia Ambiental) - Setor de Ciências da Terra, Universidade Federal do Paraná. 2008.

SIRTOLI, A.E.; SILVEIRA, C.T.; MONTOVANI, L.E.; SIRTOLI, A.R.A.; OKA-FIORI, C. Atributos do relevo derivados de modelo digital de elevação e suas relações com solos. Scientia agraria, v.9, n.3, p.317-329, 2008a.

SIRTOLI, A.E.; SILVEIRA, C.T.; MONTOVANI, L.E.; SILVA, C.R.; RIBEIRO, S.R.A.; OKA-FIORI, C. Atributos topográficos secundários no mapeamento de pedoformas. Geociências, v.21, n.1, p.63-77, 2008b. 
STRAHLER, A.N. Hypsometric analysis of erosional topography. Geol. Soc. America Bulletin, 63, p. 1117-1142. 1952.

TEN CATEN, A.; DALMOLIN, R.S.D.; RUIZ, L.F.C.; SEBEM, E.; PEREIRA, R.S. Pedometria aplicada à predição de classes de solos utilizando de regressões logísticas múltiplas. In: SIMPÓSIO BRASILEIRO DE SENSORIAMENTO REMOTO, 14. (SBSR), 2009, Natal. Anais... São José dos Campos: INPE, 2009. p. 7685-7692. DVD, On-line. ISBN 978-85-17-00044-7. Disponível em: <http://urlib.net/dpi.inpe.br/sbsr@80/2008/11.14.00.19>. Acesso em: 14 ago. 2012

TOMLIN, C.D. A Map Algebra. In Proceedings of Harvard Computer Graphics Conference, at Cambridge, Mass, 1983.

VALLADARES, G.S.; HOTT, M.C. The Use of GIS and Digital Elevation Model in Digital Soil Mapping - A Case Study from São Paulo, Brazil. In: Digital Soil Mapping with Limited Data, A.E. Hartemink et al. (eds.). Springer Science+Business Media B.V. 2008.

VIDAL-TORRADO, P.; LEPSCH, I.F.; CASTRO, S.S. Conceitos e aplicações das relações pedologia-geomorfologia em regiões tropicais úmidas. In: VIDALTORRADO P.; ALLEONI L.R.F.; COOPER M.; SILVA, A.P.; CARDOSO E.J.; PROCHNOW, L.I. (Org.). Tópicos em Ciência do Solo. Viçosa: Sociedade Brasileira de Ciência do Solo, v. IV, p. 145-192. 2005. 